\title{
Extractivismo, conflictos y defensa del territorio: el caso del corregimiento de La Toma (Cauca,Colombia)
}

\author{
MARÍa FERnANDa SAÑUdO* \\ Aida JulieTA QuiÑONES** \\ JUAN DAVID COPETE*** \\ JUAN RiCARDO DÍAZ $z^{* * * *}$ \\ NiCOLÁs VARGAS ${ }^{* * * * *}$ \\ ALIRIO CÁCERES ${ }^{* * * * *}$
}

Artículo recibido: 8 de agosto de 2015

Artículo aprobado: 10 de mayo de 2016

Doi: http://dx.doi.org/10.12804/desafios28.2.2016.10

Para citar este artículo: Sañudo, M.F., Quiñones, A.J., Copete, J.D, Díaz, J.R., Vargas, N. \& Cáceres, A. (2016). Extractivismo, conflictos y defensa del territorio: el caso del corregimiento de La Toma (Cauca-Colombia). Desafíos, 28(2), 367-409. Doi: http://dx.doi.org/10.12804/ desafios28.2.2016.10

* Profesora e investigadora, Pontificia Universidad Javeriana, Instituto Pensar, Bogotá, Colombia. Correo electrónico: msanudo@javeriana.edu.co

** Profesora de la Facultad de Comunicación y Lenguaje, Pontificia Universidad Javeriana. Correo electrónico: aquinones@javeriana.edu.co

*** Asistente de investigación del Instituto Pensar, Pontificia Universidad Javeriana. Correo electrónico: j.copete@javeriana.edu.co

**** Estudiante de la Facultad de Psicología, Pontificia Universidad Javeriana. Correo electrónico: juanchoric22@hotmail.com

***** Investigador Observatorio de territorios étnicos y campesinos. Facultad de Estudios Ambientales y Rurales. Pontificia Universidad Javeriana. Correo electrónico: vargasramireznicolas@gmail.com

****** Mesa Ecoteológica Interreligiosa de Bogotá. Correo electrónico: oikos19@gmail.com 


\title{
Resumen
}

En el presente articulo analizamos la relación entre la reconfiguración de los territorios rurales en escenarios de impulso a la minería de carácter transnacional en Colombia, así como la confrontación a la misma, a través del surgimiento y consolidación de procesos organizativos de defensa territorial. Para cumplir con tal cometido, en primer lugar nos centraremos en evidenciar las principales reformas que se ban realizado en el nivel nacionaly cómo estas operan en la reconfiguración territorial en un contexto específico: el corregimiento de La Toma, municipio de Suárez. (Cauca). En segundo lugar, atendiendo a que tal reconfiguración se sucede en el marco de tensiones y disputas, se demuestra cómo dicho proceso da lugar a la construcción de alternativas comunitarias y políticas para la defensa territorial.

Palabras clave: Conflictos sociales, resolución de conflictos, conflicto social y adaptación.

\section{Extractivism, Conflicts and Defense of Territory: The Case of the Village of La Toma (Cauca-Colombia)}

\begin{abstract}
This article analyzes the relationship between the reconfiguration of rural areas affected by transnational mining in Colombia, and the confrontation in herent in this phenomenon, through the emergence and consolidation of organizational processes of territorial defense. In order to do so, we primarily focus on the main judicial reforms that have been undertaken at the national level and how they operate in terms of the territorial reconfiguration in a specific context: the village of La Toma in the Cauca Department. In addition, we consider how such a reconfiguration takes place in the context of tensions and disputes leading to the construction of community alternatives and policies for territorial defense.
\end{abstract}

Keywords: Social conflicts, conflict resolution, adaptation. 


\title{
Extrativismo, conflitos e defensa do território: o caso do corregimento de La Toma (Cauca-Colômbia)
}

\begin{abstract}
Resumo
No presente artigo analisamos a relação entre a reconfiguração dos territórios rurais em cenários de impulso à mineração de carácter transnacional na Colômbia, assim como a confrontação à mesma, através do surgimento e consolidação de processos organizativos de defensa territorial. Para cumprir com tal obrigacaão, em primeiro lugar nos centraremos em evidenciar as principais reformas que se têm realizado no nivel nacional e como estas operam na reconfiguração territorial em um contexto especifico: o corregimento de La Toma, municipio de Suárez. (Cauca). Em segundo lugar, atendendo a que tal reconfiguração se sucede no marco de tensões e disputas, demonstra-se como dito processo ocasiona a construção de alternativas comunitárias e politicas para a defensa territorial.
\end{abstract}

Palavras-chave: Conflitos sociais, resolução de conflitos, conflito sociale adaptação.

\section{Introducción}

Desde mediados de los ochenta, América Latina se ha constituido en el laboratorio para la aplicación de una batería de reformas económicas, políticas y sociales encaminadas a configurar a los países de la región como centros "privilegiados para la radicación de grandes inversiones transnacionales"(Machado Aráoz, 2009b, p. 1). Estas deben ser entendidas como una de las estrategias, de las que se sirve el capital transnacional, para la reorganización de la dinámica de acumulación, es decir para "reasegurar a los centros mundiales de consumo y acumulación el control, acceso y disposición de los recursos naturales claves para la reproducción del sistema" (Machado Aráoz, 2009b, p. 45).

En este contexto, en Colombia se han llevado a cabo una serie de reformas encaminadas a favorecer la inversión extranjera para la 
explotación minero-energética. Entre algunos ejemplos cabe destacar: ${ }^{1}$ la sanción de leyes como la 685 de 2001 (Código de minas), mediante la cual se favorece la participación de empresas privadas en los procesos concernientes a la exploración y explotación de minerales e hidrocarburos (Díaz Ayure, 2014), y la ley 963 (Congreso de Colombia, 2005) a través de la que se instauran principios para la estabilidad a los inversionistas en Colombia, a quienes les posibilita la ampliación de los contratos, entre otras.

El mismo Estado minimiza su papel en este campo y estimula la participación del sector privado a través del desarrollo de políticas mineras. En este contexto, creó en 2011 la Agencia Nacional de Minería (Decreto 4134), instancia encargada de administrar los recursos minerales, fomentar el sector y "promocionar y otorgar títulos" (ANM, 2015). Además se explicita en los planes de desarrollo de los tres últimos mandatos presidenciales (Estado Comunitario: desarrollo para todos -2006-2010-, Prosperidad para Todos -2010-2014- y Todos por un nuevo país -2014-2018-) lineamientos para el diseño e implementación de estrategias para potenciar la productividad minera. A través del impulso a la competitividad, el desarrollo de infraestructura (construcción y adecuación de carreteras, construcción de megaproyectos -represas-), y la inversión en sectores estratégicos, se espera incrementar la inversión privada.

Los arreglos institucionales referenciados han tenido efectos importantes en lo rural, en términos de las reconfiguraciones territoriales. En este artículo nos referiremos a los procesos que acaecen en el corregimiento de la Toma, ubicado en el municipio de Suárez, norte del Cauca. En los últimos veinte años ha sido intervenido y modelado para la instauración del modelo extractivista, ${ }^{2}$ en específico para

\footnotetext{
1 Sobre estas y otras reformas y su incidencia en los procesos de transformaciones y reconfiguraciones en este aparte se explicarán de manera breve, dado que estos contenidos se desarrollarán con mayor amplitud más adelante.

2 Siguiendo a Vega Cantor (2014), este "se podría definir como el conjunto de actividades económicas -con sus correspondientes derivaciones militares, sociales, políticas, ideológicas y culturales- que posibilitan el flujo de materia, energía, biodiversidad y fuerza de trabajo
} 
la explotación de oro a gran escala. ${ }^{3}$ Las reformas y transformaciones han sido claves para que empresas como la Anglo Gold Ashanti Colombia, S.A., Gran Colombian Gold, entre otras inicien procesos de exploración y explotación de oro a gran escala. Estas, además de obtener los títulos mineros que las habilitan para iniciar la actividad, han recibido apoyo tanto de las autoridades nacionales como de las locales. Además Así mismo, el proceso ha sido coadyuvado por la implementación de estrategias de militarización, desplazamientos forzados, amenazas a líderes comunitarios, cooptación política de los habitantes de la zona, entre otros.

Estos procesos han dado lugar a conflictos en diferentes niveles, entre las comunidades locales, las empresas mineras y la institucionalidad. Estos generan una "complicada trama de producción, destrucción y reproducción de territorialidades” (Iscaro et al., 2010, p. 1), dado que los diversos actores encarnan diferentes perspectivas sobre el territorio y el uso que a este debe dársele. Mientras para los habitantes de la Toma el lugar en el que viven y trabajan adquiere una connotación de espacio vital e integral, para los foráneos, el territorio cobra un carácter mercantil y por ende este es explotable y comercializable.

Las tensiones han dado lugar al surgimiento y/o consolidación de procesos organizativos que apuntan a la construcción alternativa de defensa del territorio y se instituyen en estrategias, tal como lo afirma Escobar et al. (2001), para la construcción de iniciativas locales de defensa, cosmovisión y protección del mismo.

Tal como se sugirió antes, este estudio se realizó en el corregimiento de la Toma, municipio de Suárez (Cauca). Las actividades se

desde un territorio determinado (en este caso Colombia) hacia los centros dominantes en el capitalismo mundial"'(p. 1).

3 En la Toma, la principal fuente de sustento es la extracción del oro; sin embargo también se desarrolla producción agrícola y pecuaria. Al respecto, dentro del plan de desarrollo se señala: "la agricultura participa en un $52 \%$ de la producción del municipio, seguido de la actividad minera con un $27 \%$, el comercio con un $3 \%$ y el $18 \%$ restante está en actividades como piscicultura, avicultura, ganadería, entre otros” (Devia, 2013. p. 18). 
desarrollaron, entre enero de 2014 y abril de 2015 en el marco de un proyecto de investigación denominado Minería, procesos organizativosy defensa del territorio, auspiciado por la Pontificia Universidad Javeriana. Metodológicamente, este se planteó bajo las premisas de la Investigación - Acción - Participación (IAP). En este sentido, fue con la comunidad y los miembros del Consejo Comunitario de la Toma, con quienes por un lado se definieron los objetivos del proyecto y las estrategias para conseguirlos; y, por otro se realizó una comprensión colectiva de los procesos. La idea de ubicar como eje la construcción conjunta de conocimiento, entre investigadores y comunidad, tuvo como finalidad producir argumentos que en el corto, mediano y largo plazo ayuden a las comunidades a reforzar sus procesos de lucha por el territorio. De acuerdo con lo planteado, la recolección de información se realizó a través de técnicas participativas: grupos focales, mapeo del territorio y líneas de tiempo. Además, se realizaron entrevistas semiestructuradas a informantes clave y se llevó a cabo un ejercicio de observación participante.

En esta línea, el estudio abarcó dos dimensiones interconectadas entre sí. Con respecto a la primera y como parte de las actividades iniciales se caracterizaron y analizaron colectivamente la serie de reformas institucionales realizadas en Colombia en las últimas décadas que están encaminadas a favorecer la explotación minera a gran escala. Considerando que los cambios en el plano nacional se hacen efectivos en los niveles locales, el siguiente paso fue evidenciar cómo las reformas operaron en lo micro incidiendo en procesos de reconfiguración territorial. La comprensión de los cambios se conectó con cómo las luchas que emergen para la defensa de la Toma, además de responder a las transformaciones, buscan interpelar aquellas visiones que sobre el territorio se instauran bajo el modelo extractivista.

A continuación se expondrá el andamiaje conceptual que sirvió de soporte a la investigación; posteriormente se evidenciarán las reformas, y por último se presentarán los procesos de reconfiguración territorial y la emergencia de procesos para la defensa territorial. 


\section{Acumulación capitalista y territorio}

Para Machado (2010), durante las últimas tres décadas, la organización o reorganización de los espacios y territorios en los países de América Latina está asociada con la reorganización del capitalismo. Esta, en la actualidad, se entiende como un "proyecto de gubernamentalidad neocolonial orientado a reorganizar la apropiación desigual de la Naturaleza y a reasegurar la sostenibilidad de la acumulación a escala global” (Machado, 2010, p. 125). En este sentido, las reconfiguraciones territoriales producto de los acomodamientos y reacomodamientos institucionales y de diversa índole, pueden ser leídas como parte de las estrategias que el centro capitalista impulsa para "reasegurarse el acceso, control y disposición de las fuentes de 'recursos naturales' claves para la reproducción del sistema” (Machado, 2010, p. 125).

De acuerdo con Domínguez et al. (2006), con la complicidad estatal, evidenciada a través del impulso de reformas normativas y de diversa índole para la promoción de la inversión extranjera, se busca instituir en lo rural una "una racionalidad productiva" diferente a la campesina e indígena. Esta racionalidad requiere para su afianzamiento de la transformación de las concepciones que sobre el territorio, tienen las comunidades que lo habitan. Demanda que se transformen y desarticulen las visiones que emergen de la integración de lo material y lo cultural.

Si bien solo es después del 2000 que se suceden con fuerza procesos de privatización territorial en los países de América Latina, las reformas que comienzan en la década del ochenta, ${ }^{4}$ se constituyen en dispositivos para "lograr transformaciones radicales en las dinámicas territoriales de la periferia capitalista” (Dávalos, 2011, p. 65). En este sentido, su implementación se establece como una de las estrategias para reposicionar a la región como "uno de los núcleos centrales del desarrollo capitalista” (Composto, 2012, p. 331), en la medida en que

\footnotetext{
4 Las que transitan entre los Programas de Ajuste Estructural (1980-1990), las reformas del Estado y el cambio institucional (1990-2007); y, los procesos de privatización territorial (2000 hasta hoy) (Dávalos, P., 2011).
} 
esta es "fuente privilegiada de biodiversidad, tierra, agua, hidrocarburos y minerales" (Composto, 2012, p. 331), erigiéndose así como “Objeto de disputa al interior de la globalización” (Dávalos, 2011, p. 181). Así, las reformas han sido orientadas a la creación de espacios geográficos libres de "toda contractualidad", que limiten "el rumbo y sentido de la acumulación a escala mundial", aspecto que ha tenido como corolario "la cesión de la soberanía del Estado-Nación hacia las corporaciones y la finanza internacional” (Dávalos, 2011, p. 179).

De acuerdo con Harvey (2004), los paquetes de ajustes han propiciado un nuevo ciclo de acumulación por desposesión y con ello "la producción del espacio, la organización de nuevas divisiones territoriales de trabajo, la apertura de nuevos y más baratos complejos de recursos, de nuevos espacios dinámicos de acumulación de capital" (Harvey, 2004, p. 103).

En este contexto, el despojo a través de estrategias legales (cambios en la normativa, reformas en la estructura del Estado y jurídicas, entre otras) e ilegales (uso de la violencia, deterioro de conflictos armados y criminalización de la protesta) se instituyeron en la vía para que amplias zonas de Latinoamérica, sobre todo las de carácter rural, se integren definitivamente o continúen integradas a la lógica del capital. Así, básicamente la producción capitalista de los espacios se realiza a través de la destrucción de su coherencia local (la de los territorios), la desarticulación de los "flujos socioproductivos endolocales" (Machado Aráoz, 2009a, p. 8), y su rearticulación "como fragmentos territoriales subordinados a procesos productivos de alcance global" (Machado, 2009a, p. 8).

Así, el despojo está en la base de los procesos de acumulación en los territorios rurales. Mediante este se organiza y reorganiza el espacio. Siguiendo a Harvey (2004) este como base de la acumulación, no solo se circunscribe a los procesos de emergencia del capitalismo (acumulación primitiva), sino que persiste y se resignifica en relación con los acomodamientos que debe hacer en momentos históricos específicos. De este modo, no solamente incumbe en la "reproducción ampliada 
del capital, sino también a la violencia, la rapiña y la depredación, entre otras cosas, de los bienes naturales" (Machado, 2010, p. 183).

Las estrategias de acumulación por desposesión gravitan entre la violencia directa (desplazamiento forzados, criminalización de la protesta social, despojo violento de tierras y militarización de los territorios $)^{5}$ y la violencia simbólica, es decir el "despliegue de discursos y de prácticas para la expropiación y la incorporación de la naturaleza como un factor productivo" (Dávalos, 2011, p. 16).

Complementario a lo anterior, es de destacar que la Corte Constitucional, a través del Auto 005 de 2009 reconoce que se constituyen factores transversales del desplazamiento, "las presiones generadas por procesos mineros y agrícolas y la deficiente protección jurídica de los territorios colectivos" (p. 21). La misma Corte, basada en el informe de ACNUR (2007) señala que existe un nuevo reordenamiento territorial, el cual a través de instrumentalización armada y uso de fuerza, mediatiza el conflicto, poniendo como causa principal "la disputa por el territorio, por su ubicación en sitios de importancia geoestratégica" (p. 29).

En estos contextos las relaciones socioproductivas y las prácticas culturales son suplantadas por estructuras productivas capitalistas y tal como afirman Cruz-Coria et al. (2012, p. 16) tiene lugar "una organización espacial acorde con las necesidades de la actividad, una distribución funcional adaptada a la división del trabajo, una percepción capitalista del espacio entre la población local, nuevos hábitos y prácticas que en conjunto van produciendo espacios y configurando

\footnotetext{
5 En Colombia ha sido persistente la relación entre despojo y acaparamiento de tierras por parte de agroindustriales, terratenientes y multinacionales. El país presente uno de los niveles más altos de concentración de tierras en el mundo. En informes recientes se constata que el 10\% de propietarios son los poseedores del $77 \%$ de la tierra en el país (Pulido, 2014). De acuerdo con el informe de 2012 de la Consultoría para los Derechos Humanos y el Desplazamiento [CODHES] existe una estrecha relación entre las dinámicas del desplazamiento forzado en zonas específicas del país, con el otorgamiento de títulos mineros o la consolidación de actividades agroindustriales.
} 
paisajes que son favorables al proceso de acumulación y al ciclo de realización del capital".

Mançano Fernandes (2008) anota que la existencia de "varios ejemplos en América Latina, en la que el capital transnacional determina las políticas de desarrollo socioterritorial de los distintos países" (p. 5). Machado Aráoz agrega que "la contundencia y eficacia transformadora de los nuevos regímenes extractivistas han dado lugar a la conformación de un nuevo escenario socioterritorial regional, tanto en el plano macro de las instituciones y variables estructurales, como en nivel micro, de las subjetividades y las experiencias de la vida cotidiana" (2013, p. 33).

La penetración capitalista da lugar a nuevos patrones de relacionamiento entre las comunidades y sus territorios. Siendo este eje vital del anclaje cultural e identitario de campesinos y comunidades étnicas su modelamiento o expropiación, para la instauración de explotaciones mineras a gran escala, implican la pérdida de los referentes que los construyen y los instituyen como sujetos colectivos. Estos referentes están integrados y estructuran lo territorial también y en esa medida la avanzada extractivista debilita lo colectivo.

En línea con los planteamientos de Flórez López (2012), los procesos de reconfiguración territorial producto deben ser comprendidos como el desencuentro entre tres tipos territorialidades. El primero es el que se ancla en el bagaje cultural de una determinada comunidad. El segundo, el que emerge de la pertenencia a un estado-nación. Por último, el tercero es aquel que está amarrado a las lógicas del capital que intervienen espacios y cuerpos. Como refiere Flórez López (2012), las tensiones emergen cuando "se solapa sobre la territorialidad étnica, la territorialidad del capital de la mano de la territorialidad nacionalidad" (p. 29). En este sentido, el extractivismo se constituye en un fenómeno que irrumpe y pone en conflicto diferentes patrones de apropiación simbólica del territorio, especialmente en espacios locales. A juicio de Machado Aráoz "la contundencia y eficacia transformadora de los nuevos regímenes extractivistas han dado lugar a la conformación de un nuevo escenario socioterritorial regional, tanto en el plano macro, 
de las instituciones y variables estructurales, como en nivel micro, de las subjetividades y las experiencias de la vida cotidiana" (2013, p. 33).

Tal como diría Svampa (2013), la reconfiguración territorial en contextos extractivistas tal se sucede en un escenario altamente complejo, en el marco del cual se desencuentran lógicas territoriales (las que encarnan comunidades, empresas, funcionarios y funcionarias estatales, entre otros). Las tensiones entre visiones y sentidos no solo emergen en relación a los impactos de la práctica minera sobre el acceso a los recursos naturales, sino también por la transformación de sus formas culturales y políticas de reproducción social, que están directamente ancladas al territorio. Siguiendo a Machado (2014) hablamos de afectaciones socioterritoriales complejas que abarcan desde la destrucción de hábitats y de la biodiversidad, hasta un impacto desmedido sobre las condiciones socioproductivas tradicionales y el despojo de sus espacios vitales.

Este tipo de conflictos se constituyen en "una condición inherente al nuevo entramado societal que se empieza a diseñar"; $y$, en este panorama las "relaciones y los vínculos preestablecidos se redefinen en función de las lógicas de la explotación minera" con lo cual la "conflictividad atraviesa todos los órdenes de la vida e involucra necesariamente a todos los actores” (Machado, 2014, p. 61).

\section{Luchas territoriales y reconfiguración territorial}

Sin embargo, la fuerza que las dinámicas capitalistas y entre estas las de acumulación por desposesión ejercen en la reconfiguración territorial, también las acciones comunitarias y políticas, que emergen como formas de resistencia frente a la intervención capitalista, inciden en la producción de "otras territorialidades" o de "territorialidades alternativas" y en el mantenimiento de las "propias territorialidades". El caso de la Toma evidencia de manera directa lo anterior, en la medida en que las disputas que los actores locales han entablado con el Estado y las multinacionales, no buscan solamente la defensa del territorio, sino la posibilidad de construir formas alternativas de gestión, uso y control del mismo. Estas propuestas, bajo la perspectiva 
de esta investigación, revelan cambios en las nociones y sentidos que el espacio tiene para los habitantes del corregimiento y con ello se están ampliando los campos de significación bajo los que el espacio se produce y reproduce.

De acuerdo con lo explicitado, los sujetos que se reconocen como colectividad, en virtud de su pertenencia a una espacialidad concreta, que ha sido construida a través de su hacer económico, político, cultural y por la interacción social, en el contexto de cambios abruptos, se ven obligados a recrear o mantener sus relaciones con el territorio, dinámicas que pueden ser entendidas como procesos de apropiación o reapropiación territorial.

Estos procesos se evidencian de diversas maneras; por un lado, los sujetos traen al presente aquellos referentes históricos desde los que afianzan su permanencia en el territorio, recreando y creando sentidos y significados sobre el espacio que habitan; por otro, los sujetos interpelan a esos otros, es decir a aquellos con quienes se disputan las territorialidades. Estas interpelaciones se hacen a través de repertorios diversos, en el marco de los cuáles, como establece Díaz (2014), se articula lo comunitario y lo político, lo cultural y lo jurídico, con el fin de defender lo colectivo.

En esta defensa se producen "territorialidades propias", "territorialidades autónomas” o "territorialidades defendidas” (Svampa, 2013). En este sentido, las luchas en este ámbito deben ser comprendidas también como acciones que contribuyen a la reconfiguración espacial.

De acuerdo con Svampa (2013), la ofensiva extractivista en los países de la región ha implicado un giro en las luchas territoriales, las que, en palabras de Dávalos (2011) "en virtud de que son provocadas desde las dinámicas de la acumulación por desposesión, se convierten en disputas alrededor del sentido de acumulación del capital" (p. 36), sentido que se disputa directamente en los espacios locales.

Frente al "desmembramiento producido por la intrusión capitalista" aspecto que mina "las bases ecológicas (merma de recursos) y sociales 
(hostilidad al interior de la comunidad)" (Guerra \& Skewes, 2010, p. 462), las comunidades locales responden a través de la resignificación del paisaje y la reorientación de sus actividades productivas como base para la constitución de redes sociales para instaurar como alternativa una producción de carácter integral. Así, tal como lo afirman los autores, "los bolsones de resistencia se sostienen en la combinación de la leñería, la agricultura y ganadería, la acuicultura, la recolección de orilla y el turismo" (Guerra \& Skewes, 2010, p. 462).

Por otra parte, es de destacar que las luchas territoriales que emergen por la reorganización del espacio en contextos de expansión capitalista en los países de América Latina se caracterizan porque: 1. Recogen la larga lucha que comunidades indígenas y campesinas han entablado por el acceso a la propiedad de la tierra y del territorio. En Colombia sí bien existen diferencias considerables frente a la manera como pueblos indígenas (colectiva) y campesinos (individual) acceden a la propiedad de la tierra y frente a las visiones que tienen sobre el territorio, unos y otros han enfrentado históricamente procesos de despojo. Desde finales de los años setenta, organizaciones como la Organización Nacional de Usuarios Campesinos (ANUC) y el Consejo Regional Indígena del Cauca, entre otros, han emprendido luchas particulares por la redistribución de la tierra. Esta lucha para los campesinos tiene que ver directamente con el acceso a esta como un "recurso productivo", clave para la producción económica y la supervivencia de la economía campesina; para los pueblos indígenas además de lo anterior, estas están encaminadas a la recuperación de sus territorios ancestrales. 2. Articulan reclamaciones en torno al reconocimiento de la soberanía sobre el uso y control de los recursos naturales y en torno a la privatización del territorio. $\mathrm{Al}$ respecto, en América Latina, luchas como las emprendidas por pueblos originarios, agrupados en organizaciones como la Confederación Nacional de Indígenas del Ecuador (CONAIE) han generado movimientos que se resisten a los proyectos extractivos; estos implican la urgencia del reconocimiento de los derechos territoriales de los pueblos indígenas con las demandas de solución de las problemáticas medioambientales y la limitación del acceso a los recursos productivos, problemáticas generadas por la expansión minera (Svampa, 2012). En Colombia 
pueblos campesinos como los de Cajamarca, en Tolima, también se levantan diciendo, "No a la mina la Colosa", manifestando su defensa a los bienes comunes y a la soberanía alimentaria, en tanto se reconocen como despensa agrícola del país (Ministerio de Agricultura y Desarrollo Rural-Colombia, 2008). 3. Las demandas amarran los sentidos y significados culturales frente al territorio con el desencanto por las transformaciones que este va enfrentando con la entrada de las empresas mineras. Un ejemplo concreto es el del pueblo Mapuche en Chile, que se levanta en defensa del territorio y los bienes naturales, integrando lo material y lo simbólico en vía de la "lucha por la tierra y el territorio (Pineda, 2012, p. 136).

En relación a lo explicitado hasta el momento, estas luchas situadas y localizadas posibilitan la conjunción de miradas particulares que emergen para explicar los cambios territoriales que conlleva el modelo extractivista, es decir, integran visiones diferenciadas en la construcción de apuestas comunes: la de resistir a la imposición de raciocinios productivistas que modelan las lógicas territoriales, a la mercantilización de los recursos y los sujetos, a las transformaciones del lugar vital y al deterioro o debilitamiento de sus prácticas culturales, las que se nutren y emergen en conexión directa con el territorio.

Siguiendo a Escobar et al. (2001) las resistencias a los cambios territoriales y la emergencia de propuestas comunitarias o locales evidencia el entrelazamiento de prácticas culturales y de intereses políticos. Es decir revelan cómo a través de la puesta en escena de representaciones sobre el territorio situadas y ancladas en sus experiencias vitales apuntan a transformar las nociones hegemónicas que sobre el espacio comienzan a circular con la entrada de las multinacionales, por ejemplo.

\section{Colombia y la reconfiguración territorial}

La fuerza que toma el extractivismo en América Latina, como la principal estrategia para el desarrollo, tiene que ver directamente con el reordenamiento interno de los esquemas político-sociales de cada país, proceso orientado a producir la territorialidad necesaria para anclar el modelo extractivista en lo local (Segrelles, 1999). 
Machado (2010) señala, en este contexto, tres tipos de reformas. Las primeras son de tipo jurídico, encaminadas a regular la propiedad del subsuelo, legitimar las concesiones a la empresa privada (seguridad jurídica) y posicionar la explotación minera como de interés general por encima de la garantía de derechos. En cuanto a las segundas estas pueden resumirse en beneficios fiscales y comerciales al capital transnacional, que principalmente se caracterizan por la "desgravación de impuestos internos y de regalías mineras o su limitación a tasas insignificantes" (Machado, 2010, p. 73). El tercer grupo de reformas confluyen en la adopción de medidas relacionadas con la regulación ambiental. $^{6}$

Para el caso de Colombia, en las últimas dos décadas han tenido lugar una amplia variedad de transformaciones, en la vía señalada por Machado (2010), y entre estas, las que tienen como finalidad el hacer factible la minería transnacional. Sin embargo, para efectos de cumplir con el objetivo que nos hemos propuesto en este artículo, nos referiremos solamente a aquellas que se constituyen directamente en dispositivos directos para producir reconfiguraciones territoriales.

En primera instancia, llamamos la atención sobre las realizadas en el plano jurídico, las que han estado encaminadas a la privatización territorial. Con la formulación de la Constitución de 1991 se sientan las bases de este proceso y de las condiciones para el otorgamiento de seguridad jurídica a particulares. A través los artículos 332, 334, 360 y 80 se establece que el Estado es el propietario del subsuelo y de los recursos naturales no renovables que se encuentren en este. Bajo esta presunción, este detenta las facultades para intervenir en la explotación de los recursos naturales y decidir sobre el uso del suelo. En función de esta capacidad el Estado "tiene de un lado, la obligación de conservación de estos bienes y, de otro lado, los derechos económicos que se deriven de su explotación, y por tanto la competencia y la facultad para conceder derechos especiales de uso sobre dichos

\footnotetext{
6 Las reformas se ajustaron a las recomendaciones contenidas en la "Estrategia minera para América Latina y el Caribe" de 1997 en parte fundamento de la serie de códigos mineros que se acuñaron en varios países de América Latina.
} 
recursos, a través de concesiones, las cuales constituyen derechos subjetivos en cuanto entrañan un poder jurídico especial para el uso del respectivo bien público" (Sentencia C-983/10).

Frente a este aspecto, uno de los miembros del Consejo Comunitario, en el marco de uno de los grupos focales realizados con ellos, expresó lo siguiente: "Uno piensa que la Constitución fue una cosa muy buena para nosotros. Sí fue buena porque se nos reconocieron derechos como minorías, pero al mismo tiempo fue nociva, porque como se establece en algunas partes de esta, se limitaron las decisiones para el uso de los recursos solo a los entes estatales; las comunidades quedamos por fuera" (Extracto de entrevista a líder comunitario del corregimiento de la Toma (Cauca), 2014).

Por otra parte es de considerar cómo a través de decisiones normativas el Estado se blinda a sí mismo y a las empresas mineras frente a los conflictos de intereses que pueden emerger con las comunidades habitantes de los territorios. Si bien Colombia acoge los principios y obligaciones establecidos en el Convenio 169 de la OIT, en particular sobre el derecho a la consulta previa a comunidades étnicas, a través de la Constitución Política de Colombia de 1991 y el Decreto 1320 de 1998, estas no se han establecido como un requisito previo al otorgamiento del título, sino como uno de los requerimientos que las empresas deben cumplir para iniciar "legalmente" las exploraciones y explotaciones (Betancur, 2014). Sin embargo, la Corte Constitucional, a través de las Sentencias 652 de 1998 y T 955 de 2003 buscó subsanar los problemas referenciados, pero el Consejo de Estado consideró que dicho Decreto se ajusta a la ley, legitimando la ejecución de proyectos extractivos en territorios étnicos.

Otra de las normas clave de considerar es el Código de Minas de 2001 (Congreso de Colombia, 2001). Este se constituye en una estrategia orientada a eliminar los obstáculos y crear condiciones para una mayor participación del capital privado en los procesos extractivistas. De acuerdo con Díaz (2014), a través de este se afianzan cuestiones para el desarrollo institucional minero del país, como: 1) definición de estrategias para que Colombia se transforme en un país minero; 
2) las limitaciones del quehacer estatal sobre todo lo relacionado con las actividades de explotación; 3) propone la serie de incentivos para el fomento de la inversión privada.

Por otra parte y a través del Artículo 5 se ratifica que el Estado es dueño del subsuelo, pero se amplía tal consideración en la medida en que se establece que terceros que habiten o usen el territorio no podrán, en caso que el Estado lo titule, reclamarlo. A lo anterior se suma lo establecido en el Artículo 6 referente a que los derechos de exploración y explotación se adquieren mediante la concesión de títulos mineros, cuestión que es viable porque la industria minera (en todas sus ramas y fases) se considera de utilidad pública e interés social y "por tanto podrán decretarse a su favor, a solicitud de parte interesada y por los procedimientos establecidos en este Código, las expropiaciones de la propiedad de los bienes inmuebles y demás derechos constituidos sobre los mismos, que sean necesarios para su ejercicio y eficiente desarrollo" (Artículo 13).

De cara a que en el nivel territorial, las decisiones que se tomen en virtud del modelo de descentralización, puedan afectar la inversión privada se establece en el Artículo 37 "ninguna autoridad regional, seccional o local podrá establecer zonas del territorio que queden permanente o transitoriamente excluidas de la minería".

Esta disposición se ratifica mediante el Decreto 0934 del 9 de mayo de 2013 del Ministerio de Minas y Energía, a través del cual se estipula que el ordenamiento minero no forma parte del ordenamiento territorial, y que, por tanto, municipios y departamentos no tienen la competencia para regularlo. Lo anterior evidencia cómo el Estado central se blinda para proteger los proyectos de extracción minera del accionar local para la defensa de la autonomía territorial.

Como reacción a lo establecido en el Decreto referenciado, la Federación Colombiana de Municipios interpuso una demanda ante el Consejo de Estado, aludiendo que mediante este Decreto se está interfiriendo en los procesos de descentralización y de autonomía de los entes territoriales y, además, se está limitando el papel de las au- 
toridades locales para decidir sobre los usos del suelo. Esta demanda no surtió efecto, por lo tanto actores particulares interpusieron ante la Corte Constitucional (Entre estos ver el Expediente No. D-9700. Concepto No. 5618) demandas por la inconstitucionalidad del artículo 2 del Decreto 0934 de 2013, en la medida en que este vulnera tanto el derecho que tienen los entes territoriales para decidir sobre los usos del suelo como el derecho de participación ciudadana. Frente a lo anterior, la Corte Constitucional suspendió el Decreto referenciado, con lo cual en la actualidad carece de efectos jurídicos. Este logro, aunque no sea directamente un reconocimiento para los territorios colectivos de comunidades afrocolombianas, en la medida en que estos no detentan la figura de entidad territorial (como es el caso de los resguardos), implica que las comunidades negras conservarían un margen para por ejemplo incidir en los Planes de Desarrollo municipales o departamentales o en los POT, tal como lo establece uno de los entrevistados en el corregimiento de la Toma: "La suspensión del Decreto 0934 no nos beneficia directamente como Consejo Comunitario, pero sí nos permite que podamos participar e incidir en las decisiones que los alcaldes, por ejemplo tomen frente a la explotación minera en los territorios negros. En medio de nada se agradecen estos avances" (Extracto de entrevista a líder comunitario del corregimiento de la Toma (Cauca), 2014).

Por otra parte, pero en la vía de dar cuenta sobre las transformaciones institucionales para favorecer la extracción minera a gran escala, es de resaltar que el país ha establecido incentivos y beneficios fiscales a las empresas mineras. Rudas (2010), quien realizó el cálculo de la cantidad real que el Estado colombiano está percibiendo por regalías, demostró que teniendo en cuenta las exenciones que el Gobierno está realizando a las empresas mineras, el State take varía entre 1\% y $12 \%$. En el caso de las petroleras, Vanegas (2012) señala que en la actualidad estas disfrutan de prebendas tributarias y nadie controla su producción ni el pago de sus impuestos. Bajo el actual contrato la participación del Estado en la renta petrolera no supera el $42 \%{ }^{7}$ Sobre este aspecto, los miembros del Consejo Comunitario de la

Frente a lo anterior Rudas y Espitia (2013). afirman que en Colombia las normas fiscales tienen las siguientes ventajas tributarias sobre los impuestos a la renta a. Deducción 
Toma han hecho especial referencia. Al respecto uno de los líderes anota "No es posible que, además que se permite la entrada 'facilito' de las multinacionales a nuestros territorios, se les perdonen los impuestos y no se les cobre lo que es. Esto es indignante. El Estado colombiano está vendiendo barato al país. Vienen, se llevan todo y además no se les cobra por los daños. No sé para quien es negocio esto" (Extracto de entrevista a líder comunitario del corregimiento de la Toma (Cauca), 2014).

Complementario a lo anterior, es de anotar lo propuesto por Harvey (2004), quien establece que la intervención del territorio a través del desarrollo de infraestructura en sitios estratégicos (donde se prevé hay recursos minerales) corresponde a una de las estrategias para avanzar en la reorganización socio-territorial para favorecer la acumulación de capital a escala global. La configuración de espacios por medio del desarrollo de infraestructura en América Latina se realiza a través del proyecto Iniciativa para la Integración de la Infraestructura Regional Sudamericana (IIRSA). Esta iniciativa se fija como principal objetivo el de "organizar el espacio geográfico con base en el desarrollo de una infraestructura física de transporte terrestre, aéreo y fluvial; de oleoductos, gasoductos, hidrovías, puertos marítimos y fluviales y tendidos eléctricos y de fibra óptica, entre los más destacados" (Zibechi, 2006, [en línea]).

Con el fin de dinamizar el comercio regional, articulándolo al mercado mundial, este proyecto se entreteje a través de doce ejes de integración y desarrollo. Es de resaltar que aquellos relacionados con el desarrollo de infraestructura vial, fluvial y marítima "coinciden estratégicamente" con los corredores por dónde se transporta hidrocarburos y carbón y en territorios en los que se instauran o se instaurarán proyectos de explotación minera a cielo abierto y a gran escala. Colombia en específico se integró a este proceso desde septiembre de 2000, a través de la firma de la Declaración de Brasilia, acuerdo que emerge de la Reunión de Presidentes de América del Sur. 
Colombia se integra a esta Iniciativa a través de dos ejes: el Andino y Amazónico. En el Andino la apuesta es por el desarrollo de vías terrestres (IIRSA, 2007) para conectar a Bolivia, Colombia, Perú, Ecuador y Venezuela. En cuanto al eje Amazónico, se persigue prioritariamente el desarrollo de proyectos portuarios y de navegación para conectar los océanos pacífico y Atlántico. Desde el 2000 hasta hoy un número importante de proyectos se vienen impulsando bajo este proceso; entre estos cabe destacar la Carretera Pasto-Mocoa, el impulso a la navegación en el río Meta, la construcción del paso fronterizo entre Cúcuta-San Antonio del Táchira, la recuperación de la navegabilidad del río Magdalena, la mejora y ampliación de los puertos de Buenaventura y Tumaco, la doble calzada Buga-Buenaventura, entre otros (IIRSA, 2007).

Otra de las consideraciones que ha expuesto Díaz (2014) frente a la reconfiguración de los territorios para la expansión minera, es el desarrollo de represas con la finalidad de contar con la disposición suficiente de agua y energía para mayor eficiencia en la producción. Según documentos de la Unidad de Planeación Minero Energética (UPME), se proyecta una demanda de energía eléctrica en Colombia para el periodo de $2014-2028$ que va de $2,2 \%$ en 2014 , aumentando a 3,9\% para el 2019. Lo anterior es significativo teniendo en cuenta la correlación con zonas estratégicas para el desarrollo de la minería que, a través de su expansión, requiere un alto porcentaje de energía para su funcionamiento (Isch, 2014). En el mismo sentido, sobre los altos requerimientos en recursos hídricos, la Contraloría General de la República (Cabrera Leal y Fierro Morales, 2013), evidencia que los proyectos mineros demandan altos volúmenes de agua y uso de energía particularmente cuando se trata de megaproyectos (Vargas, 2013).

Además de las intervenciones referidas, Ceceña (2014) señala que otras corresponden a la militarización de los territorios ${ }^{8}$. De acuerdo con

\footnotetext{
8 Ceceña se basa en el informe desarrollado por Latin America working group education fund, Center for international policy (CIP) y WOLA, para el Congreso de Estados Unidos (p. 14) que, citando a Isacson et al. (2014) asevera que Colombia, ha sido el más importante receptor en materia de asistencia militar y policial durante los últimos veinte años.
} 
Vega (2012, p. 2) “en los últimos años se ha presentado un crecimiento exponencial de las fuerzas represivas del Estado para resguardar las zonas de extracción de minerales e hidrocarburos". Cabe destacar que la militarización es reforzada a través de alianzas con grupos de seguridad privada. Frente a este aspecto Fray (2014) ha denunciado sobre la serie de contratos de seguridad celebrados entre el Ministerio de Defensa, la Drummond Ltda y la Anglo Gold Ashanti Colombia S.A. Mediante estos contratos, las empresas acceden a esquemas de seguridad y de protección frente a las acciones de grupos armados.

Todos estos procesos coinciden con el incremento o permanencia de violaciones de derechos humanos (Belda et al., 2016). En el contexto de la locomotora minero energética, que fundamentalmente se inicia desde 2003 bajo los gobiernos de Álvaro Uribe Vélez y Juan Manuel Santos, los desplazamientos forzados, las muertes selectivas y el despojo, entre otras acciones contra la población civil se han constituido en una de las estrategias para el control de los territorios, que son tanto ricos en recursos naturales como ideales para los proyectos de desarrollo a gran escala (Escobar, 2010). Siguiendo a Massé y Camargo (2012) “el 80\% de las violaciones de los derechos humanos que han ocurrido en Colombia en los últimos diez años se produjeron en regiones minero-energéticas y el $87 \%$ de las personas desplazadas proceden de estos lugares"(p. 78).

La expropiación de las tierras y de los recursos naturales resulta más efectiva cuando se puede lograr, por medio de la expulsión violenta del territorio de comunidades y pueblos, hecho que lleva implícita una transformación de los derechos comunes, colectivos y públicos, en derecho privado ${ }^{9}$ (Vega, 2012).

\section{La reconfiguración territorial en lo local}

La Toma es un corregimiento del municipio de Suárez, ubicado el norte del departamento del Cauca y entre los ríos Cauca y Ovejas

\footnotetext{
9 Al hacer uso de la violencia se está haciendo referencia al uso de la intimidación, de amenazas, muertes, masacres, torturas o desplazamiento forzado.
} 
(mapa 1). Principalmente, los habitantes son afrodescendientes que poblaron el territorio desde la época colonial. Está compuesto aproximadamente por 7000 hectáreas en las que residen cerca de 1300 familias, quienes tienen como eje de su actividad económica la minería artesanal de oro, actividad que se realiza en las riberas de los ríos referenciados antes (Abreo Carrillo et al., 2011, p. 35).

Mapa 1. Municipio de la Toma (Departamento del Cauca)

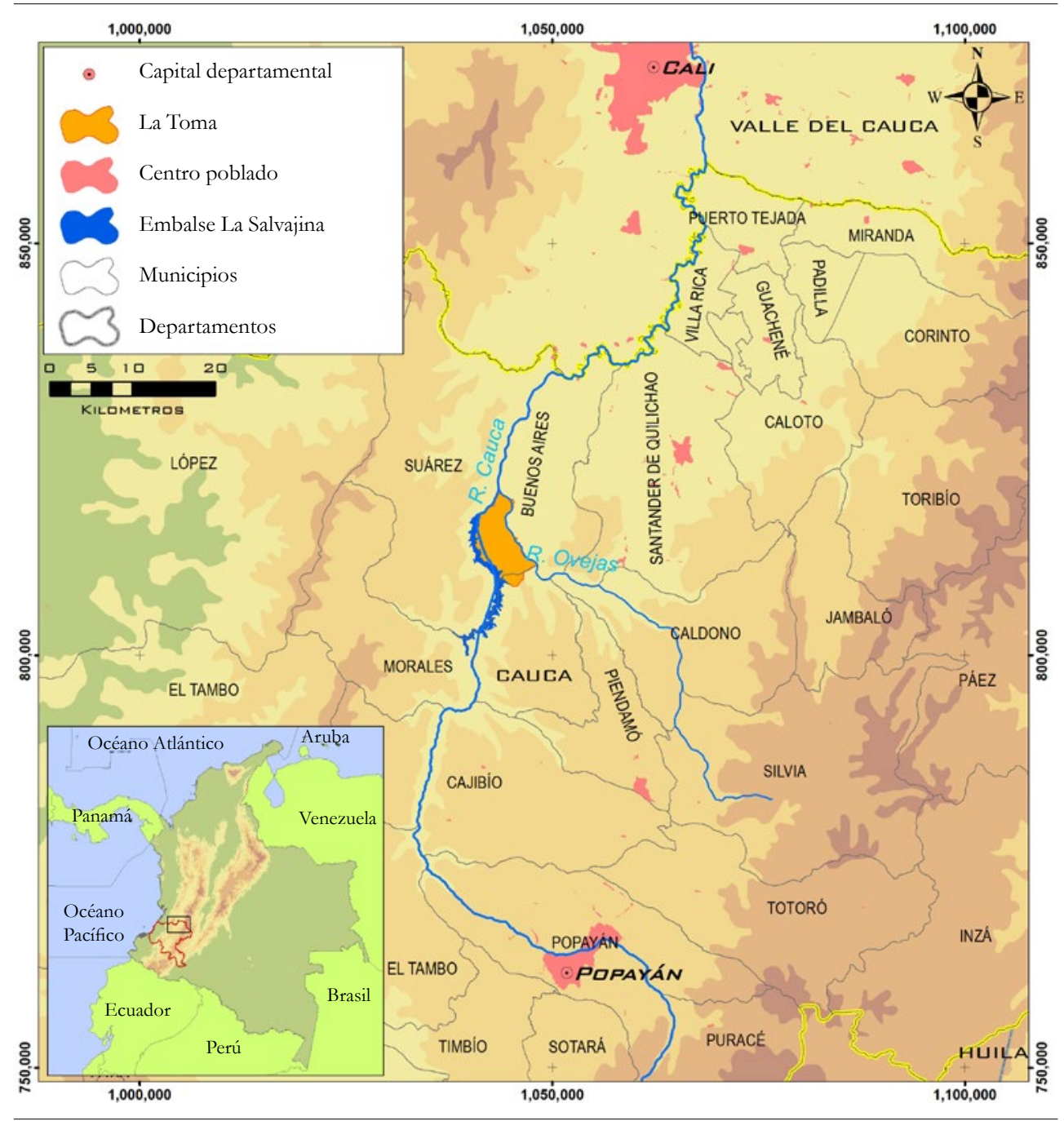

Fuente: Vargas Ramírez, 2015. 


\section{Las primeras intervenciones en el territorio y las resistencias}

En la década de los ochenta, bajo la idea de impulsar el desarrollo a través de la generación de energía, se construyó la Represa de la Salvajina sobre el río Cauca, en el corregimiento de Buenos Aires, municipio Suárez. Esta tiene una extensión de 31 kilómetros (Callejas et al., 2010) y su construcción finalizó en septiembre de 1985. Los objetivos de su construcción fueron evitar inundaciones, producir energía y mantener un bajo nivel de contaminación en la zona de extracción de agua potable. La obra fue liderada por la Corporación Autónoma Regional del Valle del Cauca (CVC), pero en 1995 esta fue enajenada por la Empresa de Energía del Pacifico S.A (EPSA). El objetivo de este traspaso fue que la CVC quedara a cargo solamente del manejo ambiental del Embalse y la empresa pública se hiciese cargo de la producción de electricidad. En el2000 EPSA vendió 63\% de sus acciones a Unión Fenosa de España (Osorio y Galíndez, 2009), la que como accionista mayoritaria en 2005 propuso reactivar el proyecto de desviación del río Ovejas (con el objetivo de potenciar el Embalse en un 20\%), propuesta que en 1997 ya se había realizado y que conllevó a que la Comunidad reaccionará, exigiera la consulta previa y se negara a aceptar el proyecto (Osorio y Galíndez, 2009).

Es de aclarar que la obra de la Salvajina se presentó ante las comunidades como una posibilidad de mejoramiento de las condiciones de vida; sin embargo, tuvo graves impactos sobre los pobladores. Entre estas se encuentran principalmente las asociadas al despojo de sus tierras, de sus medios de producción y el desplazamiento forzado. Este aspecto es así referenciado por habitantes del corregimiento "Con la Salvajina comenzaron nuestros problemas territoriales. Con la construcción de esta cambiaron muchas cosas en la vida de las personas de acá. Primero, nos quitaron las tierras, segundo porque inundaron zonas en las que sacábamos artesanalmente oro, tercero porque nos dividieron el territorio. Quedamos separados por el agua. Ya no éramos vecinos de tierra, sino de agua. Otra gente se tuvo que ir, se desplazó a Cali y a vivir muy mal" (Extracto de entrevista a líder comunitario del corregimiento de la Toma (Cauca), 2014). 
Los impactos pretendieron ser solucionados a través de la firma de acuerdos entre la población y las entidades gubernamentales. Mediante el Acta 86 de 1986 se establecieron los criterios para compensar los daños causados; estos se constituyeron en el eje para la formulación del Plan de Desarrollo Regional, sancionado mediante Decreto 3000 del mismo año (Corte Constitucional de Colombia, 2014). Pese a los acuerdos, se advierte su incumplimiento.

Frente a esta situación la Corte Constitucional (2014) se pronuncia, aludiendo que "observa que desde la construcción del proyecto de la Central Hidroeléctrica Salvajina, las poblaciones aledañas sufrieron de cambios trascendentales en sus vidas por el desplazamiento y la transformación del entorno al que fueron sometidas" (p. 5). En tal sentido, uno de los miembros del Consejo Comunitario de la Toma, ${ }^{10}$ señala al respecto: "mucha gente terminó en la delincuencia porque no encontró otra salida de sobrevivencia" (Extracto de entrevista a líder comunitario del corregimiento de la Toma (Cauca), 2014).

En conexión con el objetivo de este documento, comprendemos la construcción de la Salvajina como un proceso de intervención del espacio para adecuarlo a las necesidades de la explotación de oro a gran escala. Con su construcción se dispuso del agua del río Cauca para 1) generar energía, y 2) contar con grandes volúmenes de este recurso, los que posteriormente serían usados en los procesos de explotación de oro por parte de empresas multinacionales como la Anglo Gold Ashanti (Díaz, 2014).

Otro aspecto a resaltar es que desde la construcción de la Salvajina, el territorio ha estado ocupado permanentemente por el ejército. El objetivo de esta ocupación ha sido brindar seguridad a la inversión privada. La ubicación de bases militares en la Salvajina (San Miguel

\footnotetext{
10 Los Consejos Comunitarios son reconocidos por la Ley 70 (Congreso de Colombia, 1993). Tomando el artículo $3^{\circ}$, del Decreto 1745 de 1995, se destaca que los Consejos Comunitarios están integrados por una "Comunidad Negra". Se constituyen con persona jurídica y ejercen como máxima autoridad de administración interna al interior de los territorios de comunidades negras" (Consejo comunitario La Toma. Municipio de Suárez, 2011, p. 1).
} 
y Polvorines) en el 2000 coincide con la entrada de las Fuerzas Armadas Revolucionarias de Colombia (FARC) en la zona. Con la presencia militar se buscó controlar las acciones de esta guerrilla y con ello, minimizar las posibilidades de riesgo frente a eventos terroristas (Rosero, 2008).

Así, tal como aseguran los habitantes de la zona, la presencia del ejército no ha sido, precisamente, para protegerlos. Pese al riesgo que enfrenta la población, los militares solo reaccionaron cuando "la guerrilla se tomó la Salvajina y amenazó con volar la casa de máquinas de la central hidroeléctrica" (Rosero, 2008, p. 34); la reacción se resumió en que reforzaron la base de San Miguel, ampliándola desde el muro de la represa hacia el resto de la cordillera.

En el escenario delineado hasta el momento, las intervenciones han dado lugar a la reestructuración de las relaciones entre el territorio y las personas que lo habitan, que tal como lo establecen Ararat et al. (2013) "la inundación de las tierras ubicadas en las orillas del río Cauca trajo como consecuencia cambios profundos en la relación de los pobladores con la tierra y con el río; la producción agrícola, la minería, la pesca y la navegación, que dependían del río Cauca, se acabaron. Las relaciones sociales basadas en redes construidas a lo largo de siglos entre los habitantes de ambas orillas del río, se vieron truncadas por la represa. Y para hacer aún más crítica la situación, muchas personas se vieron forzadas a buscar alternativas de trabajo en lugares distantes, luego de ser despojadas de sus tierras” (p. 151).

\section{La irrupción de la minería transnacional}

Un segundo momento que marca la reconfiguración del territorio es la titulación de este a particulares y a empresas multinacionales. Actualmente en esta zona se encuentran cerca de 6.500 hectáreas $(93 \%$ del corregimiento) otorgadas o en proceso de solicitud a terceros para la explotación (mapa 2 y mapa 3): 
392 I M. Sañudo, A. Quiñones, J. Copete, J. Díaz, N. Vargas, A. Cáceres

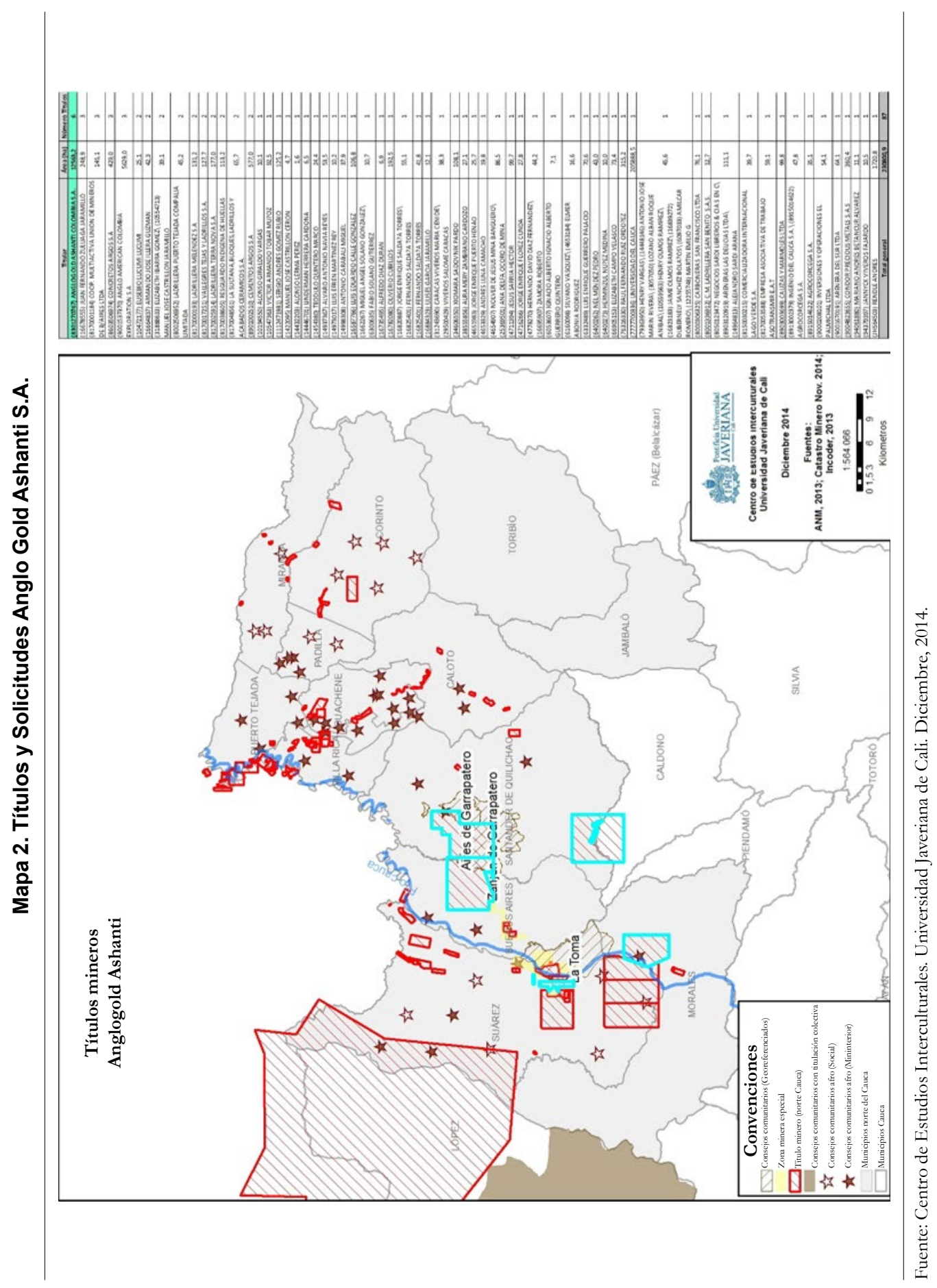




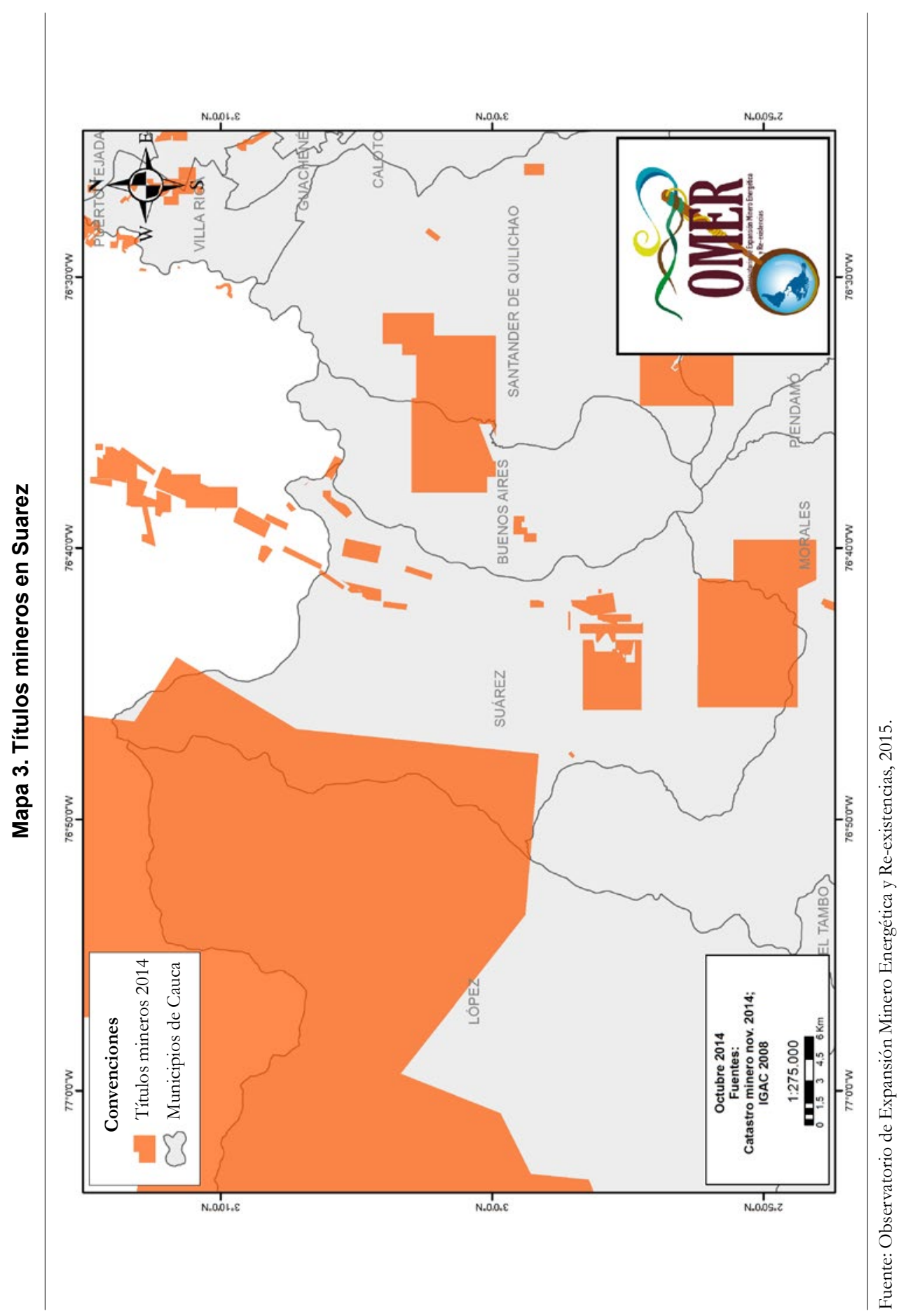


Es de recalcar que los habitantes de este corregimiento han soportado en gran parte su actividad económica en la explotación artesanal de oro y en este sentido, la concesión de los títulos no solo significa una amenaza de despojo del territorio, sino también, un perjuicio, pues afecta sus prácticas productivas, tal como se manifestó en uno de los grupos focales realizados "Si ya perdimos bastante con la Salvajina, ahora con la entrada de las grandes mineras vamos a perder mucho más. El territorio, el río Ovejas, del que muchas familias sacan su sustento. También los bosques" (Extracto de entrevista a líder comunitario del corregimiento de la Toma (Cauca), 2014).

En este contexto el uso de la violencia ha sido una constante. Desde que se empezaron a entregar los títulos, las amenazas y violaciones de los derechos humanos no han cesado. En opinión de Rico (2010), de la Silla Vacía, "la gente de La Toma está expuesta a las amenazas y violencia por parte de actores armados que parecen respaldar las explotaciones del oro en cabeza de los privados"([n línea]). Este hecho se verifica a través de una publicación de El Espectador (2011), en la cual se cuenta que ante la entrada de unas retroexcavadoras que facilitan la extracción de oro, en un lugar dentro del corregimiento de La Toma, varios mineros ancestrales ${ }^{11}$ tuvieron que suspender su actividad, por amenazas de actores armados ilegales. Este hecho es referenciado por una de las lideresas comunitaria de la zona: "al oído que acá hay oro van entrando los mineros ilegales también, porque uno sabe que con la entrega de los títulos a las grandes mineras, inmediatamente aparecen como chulos por donde sea y no se sabe cómo, los particulares con las retro. Estos entran amenazando a la gente del lugar, se van apropiando de pedazos de los ríos, van amenazando a los mineros tradicionales y se van apropiando poco a poco del río." (Extracto de entrevista a líder comunitario del corregimiento de la Toma (Cauca), 2014).

Es de destacar como antecedente que en este escenario, concretamente en 2007, INGEOMINAS otorgó a un particular la explotación de

\footnotetext{
11 La minería ancestral, se define como aquella que hace parte de la cultura de los pueblos, de su identidad y de la tradición productiva, además es una representación simbólica que los pueblos han apropiado durante siglos (González, 2013).
} 
una serie de yacimientos de oro en la zona (Colombia, 2010). Posterior a esto, se concedió amparo administrativo al particular" y se ordenó "inmediata suspensión de las actividades de explotación que adelantan dentro de la licencia" (Colombia, 2010), provocando con esto que los mineros fueran desalojados por estar ejerciendo según la institucionalidad, labores de minería ilegal, siendo acusados de ser 'poseedores de mala fe'. Sin embargo, a través de diversas acciones jurídicas y sociales los habitantes han logrado frenar momentáneamente la entrada de las empresas.

La Corte Constitucional, como respuesta a una tutela interpuesta en mayo 20 de 2010 por representantes del Consejo Comunitario, profirió Sentencia 1045A del 14 de diciembre de 2010, mediante la que ordenó a INGEOMINAS suspender todas las licencias de explotación minera en La Toma hasta cuando se realizara el proceso de consulta previa a las comunidades afrodescendientes (Colombia, 2010). Esta ganancia, si bien es limitada, para los miembros del Consejo Comunitario es un avance en término de blindarse frente a la arremetida de las empresas mineras, tal como lo manifiesta uno de ellos "Ya sabemos que la Sentencia nos da ventaja, pero también sabemos que esto no resuelve los problemas, solo los pospone. La ventaja que estamos sacando de esto es que dilatamos la Consulta para poder ganar tiempo y buscar otras estrategias para defender nuestro territorio" (Extracto de entrevista a líder comunitario del corregimiento de la Toma (Cauca), 2014.

En esta vía de análisis, también es importante enunciar que existen un conjunto de mecanismos de cooptación que han sido ejecutados directamente por la Anglo Gold Ashanti. Esta, según lo expresa uno de los pobladores, ha tratado de incidir en la formulación del Plan de Desarrollo de Suárez y en el POT. También ha buscado que los funcionarios de la Alcaldía de Suarez y miembros del Consejo establezcan criterios de ordenamiento del territorio que los beneficie.

De igual forma, han sobornado a líderes comunitarios para debilitar las organizaciones sociales y la defensa territorial (Notiagen - Colectivo Punto de Fuga, 2012). Lo anterior es corroborado a través de 
un aparte de una de las entrevistas en la que un líder manifiesta "El mecanismo de ellos es contactar a los líderes; siempre lo que han buscado es entrar a las comunidades ofreciendo dádivas y ese ha sido uno de los mecanismos, pero la verdad la gente ha estado muy consciente de la realidad" (Extracto de entrevista a líder comunitario del corregimiento de la Toma (Cauca), 2014).

En este escenario, otro aspecto de vital importancia a considerar es la entrada a la región, en 2014, de un grupo de mineros ilegales al Río Ovejas, específicamente a las zonas conocidas como Remolino, Canoa, San Juan y el Hato Santa Marta (Red por la Justicia ambiental, 2014), sin que ninguna autoridad tomara las medidas necesarias para detener dicho ingreso y menos, las operaciones de explotación que allí se inician. Frente a este hecho, el Proceso de Comunidades Negras $(\mathrm{PCN})^{12}$ realizó una denuncia, señalando que "en el corregimiento de La Toma, municipio de Suarez, al Norte del Cauca, ingresaban 12 retroexcavadoras destruyendo el patrimonio natural y herencia de las tomeñas y los tomeños" (W Radio, 2014).

Esta situación dio comienzo a una escalada de conflictos sociales, ambientales y de seguridad, cuyo objetivo es desplazar a la comunidad, tal como ha sucedido en otras regiones del país, en las que a través de la minería ilegal se "despejan" zonas, fortaleciendo con esto el conflicto, a fin de provocar el despojo territorial para extraer los recursos naturales.

\section{El agenciamiento político y la defensa comunitaria del territorio}

Las resistencias para la defensa del territorio tienen antecedentes en los procesos organizativos que emergieron frente a los impactos de la construcción de la Salvajina. Uno de los líderes de La Toma refiere al

\footnotetext{
12 El Proceso de Comunidades Negras-PCN, se consolidó a partir del reconocimiento en Colombia como una Nación pluriétnica y multicultural, según declara la Constitución Política de 1991. El PCN está conformado por "120 organizaciones étnico - territoriales, entre Consejos Comunitarios y organizaciones de base” (Organización de Naciones Unidas, 2011).
} 
respecto "el proceso organizativo parte de los procesos que surgieron con la pretensión de desviación del rio Ovejas, con la construcción del embalse de la Salvajina. Entonces ya había una experiencia, pero nos tocó hacer muchos más esfuerzos en el momento en el que aparece la multinacional, y nos toca buscar ayuda a nivel nacional e internacional, porque la cosa se puso complicada" (Extracto de entrevista a líder comunitario del corregimiento de la Toma (Cauca), 2014).

En 2010, cuando se dio la orden de desalojo de los mineros, 500 de ellos bloquearon la carretera en defensa de su territorio. Para terminar con la protesta, las autoridades locales enviaron el Escuadrón Antidisturbios, el cual, mediante maniobras violentas, expulsó a las personas (El País, 2010). Sin embargo, los procesos organizativos continuaron y se ampararon bajo el Convenio 160 de la OIT y la Ley 70 de 1993 (Congreso de Colombia, 1993), instrumentos mediante los que se reconocen los derechos territoriales de comunidades étnicas. Bajo este amparo una de las líderes de la Comunidad interpone una Tutela ante la Corte Constitucional. Esta instancia profiere la Sentencia T1045A/10, mediante la que se señala que previo a procesos de exploración y explotación de un proyecto minero en territorio étnicos, el Estado debe realizar la consulta previa con las comunidades de la zona, y que mientras tal proceso no se surta, las exploraciones deben parar (Colombia, 2010, p. 1).

Mediante esto se logró frenar la entrada de las multinacionales al territorio y se constituye en el recurso que posibilitó el fortalecimiento organizativo en torno a un proyecto en común: la defensa del territorio. Además, lo proferido en la Sentencia se constituyó en el dispositivo que permitió la emergencia de propuestas encaminadas a la autonomía territorial.

Como acción colectiva complementaria, las comunidades adelantan procesos para adquirir la titulación colectiva del territorio bajo los derechos contemplados en la Ley 70 de $1993 .{ }^{13}$ Esta se constituye en

13 La Ley 70 de 1993 refiere el reconocimiento de las comunidades negras que han ocupado tierras baldías en zonas rurales de las riberas de la Cuenca del Pacífico. 
una herramienta contundente para la defensa territorial. No obstante, la adquisición de los predios no ha sido posible, debido a que algunas personas de la comunidad no quieren ceder la propiedad individual para la constitución de un territorio colectivo. Claramente, este aspecto evidencia tensiones entre las representaciones sobre el acceso individual a la tierra y el acceso colectivo. Este aspecto es referenciado en una de las entrevistas realizadas en la Toma "Si queremos defender el territorio, debemos tenerlo colectivo, pero mucha gente no quiere eso. No quiere vender sus propiedades. No entienden que para defendernos debemos hacer sacrificios. A veces esto lo entienden más los de afuera que los de adentro. Esto ha sido un problema porque mientras no tengamos colectivo el territorio, la defensa se ve limitada" (Extracto de entrevista a líder comunitario del corregimiento de la Toma (Cauca), 2014).

En este contexto, el Consejo Comunitario ha jugado un importante papel en la apuesta por la constitución de un territorio en términos de autonomía, es decir, como un espacio vital que debe ser defendido por medio de prácticas que van más allá de la normatividad. Ejemplo de esto es que la defensa que hace esta instancia ha sido acompañada de la reconstrucción de la memoria del territorio, es decir de la construcción colectiva de una historia común de arraigo a un espacio vital, el que tradicionalmente ha sido vivido y con el que han establecido una relación cercana mediante la minería ancestral. Lo anterior puede ser corroborado por el testimonio de un miembro del consejo comunitario: "la gente se olvida de sucesos anteriores, evitando que la lucha continúe y no se frene; por ello hay que contar la historia para que no se vuelva a repetir, la historia de la defensa del territorio" (Extracto de entrevista a líder comunitario del corregimiento de la Toma (Cauca), 2014).

En parte la construcción de memoria del territorio se construye aludiendo a las tradiciones de movilización y resistencia de los pobladores de La Toma en momentos coyunturales, como los vividos en los procesos de construcción de la Salvajina. A nuestro modo de ver, esto evidencia la construcción de significados sobre la defensa del territorio, los que trascienden los discursos normativos y se orientan 
hacia procesos prácticos organizativos de movilización y resistencia. Este aspecto es referenciado por una de las lideresas del Consejo Comunitario "Históricamente no ha sido solamente la ley. La ley ha estado ahí, pero pues en algunos momentos no ha sido posible acceder a esta y entonces se han usado recursos paralelos. La Toma no puede definirse solamente en su fortaleza en términos legislativos, sino también en su capacidad de movilización y resistencia, y esto es sobre lo que tenemos que hacer memoria para encontrar otras maneras de defendernos de la arremetida transnacional" (Extracto de entrevista a líder comunitario del corregimiento de la Toma (Cauca), 2014).

En esta vía, se han utilizado prácticas culturales como la danza o la música para generar conciencia en la población joven de la comunidad sobre la importancia de la defensa y el arraigo territorial. Un joven de la zona refiere al respecto "Yo miraba las reuniones y decía: que hartera. Pero me metí al grupo de danza y empecé a asistir a las reuniones del consejo enterándome, de manera involuntaria, de las problemáticas, lo que despertó mi interés en la causa" (Extracto de entrevista a líder comunitario del corregimiento de la Toma (Cauca), 2014). Éste tipo de prácticas, que en muchas ocasiones no parecen corresponder con acciones políticas y organizativas, han resultado vitales para vincular las nuevas generaciones al proceso de defensa del territorio y de arraigo con este.

Por otra parte, y frente a las problemáticas que trae aparejadas la minería ilegal (presencia de retroexcavadoras en el río Ovejas), los miembros del Consejo Comunitario han buscado llegar a acuerdos con los dueños de los predios en los que los actores foráneos explotan ilegalmente oro. Mediante esta táctica se busca que los propietarios tomen conciencia de lo peligroso que resulta para la comunidad y para las luchas por el territorio el que permitan que estas prácticas se realicen. En este contexto, se ha buscado el que estas personas integren los procesos de movilización y organizativos, con el fin de que tomen conciencia sobre la importancia que tiene el defender de los foráneos el espacio vital (Extracto de entrevista a líder comunitario del corregimiento de la Toma (Cauca), 2014). Bajo esta lógica de defensa del territorio de la presencia de actores externos que no solo corres- 
ponden a las multinacionales, sino también a los mineros ilegales, las comunidades han reaccionado por la vía de hecho, quemando las retroexcavadoras. Esta acción se dinamiza después de agotar los canales normativos sin encontrar respuesta efectiva: "Las quemamos porque el gobierno es corrupto y no hace nada" (Extracto de entrevista a líder comunitario del corregimiento de la Toma (Cauca), 2014).).

Sin embargo, las acciones también evidencian problemáticas que limitan el agenciamiento. En el marco de este proceso se incrementaron las amenazas a miembros del Consejo y las acciones violentas contra la comunidad. Al respecto, un miembro del consejo comunitario afirma: "Si se quema una maquina se tiene ya la excusa para matar" (Extracto de entrevista a líder comunitario del corregimiento de la Toma (Cauca), 2014). El agenciamiento político, aunque logra sustentar prácticas alternativas para la defensa territorial, genera reacciones adversas para la comunidad, las que a su vez lo limitan. Estas tienen como objetivo generar miedo colectivo para frenar las acciones. Uno de los entrevistados establece al respecto: "Debido a las actividades que ha venido adelantando el Consejo, se han presentado amenazas de muerte a los líderes. Entonces, eso lo que hace es que el proceso se debilite, porque la gente debe salir del territorio" (Extracto de entrevista a líder comunitario del corregimiento de la Toma (Cauca), 2014).

Estas acciones también tienen como fin dividir a la comunidad e impedir que el Consejo Comunitario continúe como sujeto colectivo con poder para avanzar en la autonomía territorial. Lo anterior se corrobora cuando un miembro del Consejo afirma: "No todas las veredas de La Toma están comprometidas. Hay mucha gente de otras veredas que trabajan con la maquinaria y nos dicen que dejemos de ser sapos, que dejemos trabajar" (Extracto de entrevista a líder comunitario del corregimiento de la Toma (Cauca), 2014).

En el marco de las acciones colectivas de resistencia por la defensa del territorio es de destacar el proceso denominado "La Movilización de las Mujeres Afrodescendientes por el Cuidado de la Vida y los Territorios Ancestrales", en el marco del cual algunas lideresas de 
La Toma han jugado un papel fundamental. Este emerge en el 2014 como una estrategia colectiva para la defensa los territorios colectivos del Norte del Cauca. Si bien, la movilización es una respuesta directa a la irrupción de la minería ilegal en las cuencas de los ríos Cauca y Ovejas, esta tiene algunos antecedentes que es importante rescatar, entre estos la tragedia en la mina ilegal de San Antonio en Santander de Quilichao (2 de mayo de 2014), la no garantía del derecho a la consulta previa, el incumplimiento de diversos acuerdos firmados con el Gobierno nacional que integran derechos como la implementación del auto 005 de 2009 proferido por la Corte Constitucional y los acuerdos del 7 de mayo del 2014 desde los que se planteó atender los efectos de la tragedia mencionada.

El 17 de Noviembre de 2014 iniciaron la marcha en Santander de Quilichao y terminaron en Bogotá en la primera semana de diciembre de 2014. Caminaron acompañadas de diversos sectores sociales e instituciones como la Defensoría del Pueblo y de la Guardia Cimarrona. ${ }^{14}$ En el marco de este proceso, las mujeres señalaban que esta movilización lleva la sumatoria de acuerdos incumplidos y problemáticas que han venido escalando sobre el Cauca. De este modo aseveran: "La problemática minera es un problema de carácter nacional que no se limita a retroexcavadoras sin permisos legales ni explotación del oro. En el Norte del Cauca hay 271 concesiones otorgadas para la explotación de minerales. Estas concesiones, (...), tienen impactos ambientales, territoriales y culturales graves para las comunidades Afrodescendientes y han violado el derecho a la consulta y consentimiento previos que debe surtirse con las comunidades étnicas" (Movilización de Mujeres Afrodescendientes por el Cuidado de la Vida y los Territorios Ancestrales, 2014, p. 4).

Las mujeres señalan a través de un comunicado "Nuestro amor a la vida es más grande que nuestro temor a la muerte (...). No aguantamos

\footnotetext{
14 La guardia cimarrona es una estrategia de seguridad que los pueblos negros que, inspirados en los procesos palanqueros, han creado como mecanismo de protección comunitaria y territorial. La guardia se asemeja a la guardia indígena del pueblo Nasa, con quienes los habitantes de Suárez han compartido experiencias de lucha por la defensa territorial.
} 
más tener que salir corriendo a media noche por las amenazas, no aguantamos más que después de tanto tiempo, no se entienda que no queremos salir de los territorios en donde tenemos sembrados el ombligo" (Movilización de Mujeres por el Cuidado de la Vida y los Territorios Ancestrales, 2014, p. 4).

\section{Conclusiones}

Cuando se pregunta acerca de la influencia de las instituciones en la relación existente entre la comunidad y el territorio de La Toma, uno de sus líderes responde: "La verdad, los decretos y resoluciones que saca el gobierno realmente no favorecen en nada a la comunidad" (Extracto de entrevista a líder comunitario del corregimiento de la Toma (Cauca), 2014). Esta idea se confirma con la puesta en marcha y proyección de Colombia como país minero. Tanto las políticas, como las directrices encaminadas al fortalecimiento de este sector no apuntan a la defensa de las personas que viven en los territorios que han sido concedidos. La apuesta es por insertar al país bajo la modalidad de un país minero en el contexto internacional. Está claro que los principales incentivos se dan a las multinacionales; contrariamente el Estado persigue y ataca la minería tradicional.

Si bien este proceso es altamente negativo, como vimos a lo largo del artículo, también posibilita que las comunidades se activen organizativamente y construyan estrategias alternativas para la defensa del territorio y la autonomía. Bajo este amparo, los lazos de pertenencia de la comunidad con el territorio se van afianzando y fortaleciendo en tanto ellos, van ampliando y multiplicando las formas, bajo las cuales pueden defenderse y defender su espacio vital de la explotación minera a gran escala.

Así, la defensa territorial se convierte en el centro de la vida. La misma comunidad enuncia "El Territorio es la Vida, la Vida no se vende, se ama y se defiende" (Agencia Prensa Rural, 2014). Por lo mismo las estrategias que se han creado en su defensa recogen su saber ancestral, el cual se reconoce como conocimiento legado y transmitido desde los antepasados, integrando cosmovisión y cultura (Fernández, 2013). 
Tal como se pudo observar en anteriores apartes, las acciones que se han adelantado para defender su territorio van desde aspectos como campañas de sensibilización acerca de los impactos que implicaría el desarrollo de la extracción de oro a gran escala en el territorio, hasta acciones jurídicas, que son apoyadas por movilizaciones sociales, y estrategias de visibilización a nivel nacional e internacional, que tienen por objetivo ampliar la red de apoyo para la comunidad de La Toma.

De los resultados de ese proceso depende para muchos continuar viviendo o no en su espacio vital, el tener que desplazarse o incluso confinarse, el tener que cambiar su actividad productiva, el romper su núcleo social y familiar, y otras tantas cosas que suponen retos ante los cuales los afrodescendientes de La Toma prefieren hacer todo lo posible para truncar e impedir la extracción de oro a manos de las multinacionales.

\section{Referencias}

Abreo Carrillo, A.C., Antonio Rosero, E. F., Lam, Y. \& Rodríguez Garavito, C. (2011). La disputa por los recursos naturales en los territorios afrocolombianos. El caso de Buenos Aires y Suarez (Cauca) desde una perspectiva de derechos bumanos. Bogotá D.C.: Observatorio de Discriminación Racial.

Agencia Prensa Rural. (2014). Movilización de mujeres afrodescendientes por el cuidado de la vida y los territorios ancestrales. Recuperado de http://prensarural.org/spip/spip.php?article15491: Agencia Prensa Rural

Agencia Nacional de Minería. (s/f). Agencia. Misión y Visión. Recuperado de http://www.anm.gov.co/?q=agencia $/ \mathrm{mision}$

Ararat, L., Mina, E., Rojas, A., Solarte, A. M., Vanegas, G., Vargas, L. A. \& Vega, A. (2013). La Toma. Historias de territorio, resistencia y autonomía en la cuenca del Alto Cauca. Bogotá D.C.: Observatorio de Territorios Étnicos \& Consejo Comunitario Afrodescendiente del corregimiento de La Toma.

Belda-Miquel, S., Boni, A., \& Sañudo, M.F. (2016). Hacia una cooperación internacional transformadora. Solidaridades con los movimientos sociales por los derechos bumanos en colombia. Barcelona: Icaria editorial, S. A.

BETANCUR, A.C. (2014). La consulta previa a los pueblos indigenas. De la participación democrática a la expropiación de territorios. Recuperado de http:// 
observatorioetnicocecoin.org.co/cecoin/index.php?option=com content\&view $=$ article\&id $=344: 1 a-$ consulta-previa-a-los-pueblosindigenas-de-la-participacion-democratica-a-la-expropiacion-deterritorios\&catid $=55$ : consulta-previa\&Itemid $=121$

Cabrera Leal, M. \& Fierro Morales, J. (2013). Implicaciones ambientales y sociales del modelo extractivista en colombia. En L. G. Garay Salamanca (Dir.), Minería en Colombia. Fundamentos para superar el modelo extractivista, (pp. 89-123). Bogotá D.C.: Contraloría General de la República.

Callejas, C. R., Santacruz, S., Bocanegra, R. A. \& Sandoval, M. C. (2010). Incidencia del embalse de Salvajina sobre el régimen de caudales del río Cauca en su valle alto. Ingeniería de Recursos Naturales y del Ambiente 9, 89-99.

Ceceña, A. E. (Diciembre, 2014). La dominación de espectro completo sobre América. Patria, (1), 43-59.

Centro de Estudios Interculturales. (2014) Títulos y Solicitudes Anglo Gold Ashanti S.A [Mapa]. Universidad Javeriana de Cali. Diciembre.

Colombia, Corte Constitucional. Sentencia 1045A/10. (4 de diciembre de 2010).

Colombia, Congreso de Colombia. Ley 685 de 2001. Código de Minas. (17 de agosto de 2001). Recuperado de https://www.minambiente.gov. co/images/normativa/leyes/2001/ley_0685_2001.pdf

Colombia, Congreso de Colombia. (1993). Ley 70. Por la cual se desarrolla el artículo transitorio 55 de la Constitución Politica. (Agosto 27 de 1993). DIARIO OFICIAL. AÑO CXXIX. N. 41013. 31, AGOSTO, 1993. Recuperado de http://www.alcaldiabogota.gov.co/sisjur/normas/ Norma1.jsp?i $=7388$

Colombia, Corte Constitucional. Auto 005/09. Protección de derechos fundamentales de la población afrodescendiente víctima del desplazamiento forzado en el marco de superación del estado de cosas inconstitucional declarado en sentencia T-025/04. (26 de enero de 2009).

Colombia, Corte Constitucional. Sentencia T-462A/14. Marco normativo de las licencias ambientales en Colombia. (8 de julio de 2014). Recuperado de http:/ /www.corteconstitucional.gov.co/relatoria/2014/t462a-14.htm

Consejo Comunitario La Toma. Municipio de Suárez. (2011). Reglamento interno para la administración, gobernabilidad, autonomía, de la comunidad afrodescendiente del consejo comunitario La Toma. República de Colombia. Recupe- 
rado de http://www.nsi-ins.ca/wp-content/uploads/2012/11/2012Experiencia-de-la-Toma-Suarez-reglamento-interno.pdf. [Accessed 5 Oct 2015].

Composto, C. (2012). Acumulación por despojo y neoextractivismo en América Latina. Una reflexión crítica acerca del estado y los movimientos socio-ambientales en el nuevo siglo. Astrolabio (8), 323-352. Cruz-Coria, E., Zizumbo-Villarreal, L., Cruz-Jiménez, G. \& QuintanillaMontoya, A. L. (2012). Las dinámicas de dominación capitalista en el espacio rural: la configuración de paisajes turísticos. Cuadernos de Desarrollo Rural, 9(69), 151-174.

Dávalos, P. (2011). La democracia disciplinaria: el proyecto posneoliberalpara América Latina. Quito: Cooperación para el Desarrollo de la Educación Universitaria (CODEU).

Díaz Ayure, J. R. (2014). Extractivismo, instituciones y territorio. Un análisis acerca de esta relación no tan obvia. (Tesis pregrado, Pontificia Universidad Javeriana, Bogotá, Colombia).

Domínguez, D., Lapegna, P. \& Sabatino, P. (2006). Un futuro presente: las luchas territoriales. Revista Nómadas (24), 239-246.

El País. (2010). Mineros de Suárezprotestan por desalojo. Recuperado de http:// historico.elpais.com.co/paisonline/notas/Mayo222010/nal1.html

El Espectador (2011). Amenazas de muerte y minería ilegal. Recuperado de http:/ / www.elespectador.com/noticias/judicial/amenazas-de-muertey-mineria-ilegal-articulo-269734

Escobar, A., Álvarez, S. E. \& Dagnino, E. (2001). Lo cultural y lo político en los movimientos sociales latinoamericanos. En A. Escobar, S.E. Álvarez, \& E. Dagnino (Eds.), Politica cultural \& cultura política. Una nueva mirada sobre los movimientos sociales latinoamericanos (pp. 17-48). Bogotá: Taurus ICANH.

Escobar, A. (2010). Territorios de diferencia: lugar, movimientos, vida, redes. Popayán: Envión editores.

Fernández, G. (2013). ¿De qué hablamos cuando hablamos de Sabiduría Ancestral. Recuperado de https://movimientochamanico.wordpress. com/2013/04/23/de-que-hablamos-cuando-hablamos-de-sabiduriaancestral-3/

Flórez López, J. A. (2012). Territorialidad étnica, territorialidad colombiana y territorialidad del capital. En J.G. Ferro \& G. Tobón (Eds.), Auto- 
nomias Territoriales: Experiencias y Desafios (1 Ed.) (p. 285-296). Bogotá D.C.: Observatorio de Territorios Étnicos.

Fray, J. (2014). Cuestionan contratos de seguridad entre Estado y multinacionales. Recuperado de http://www.caracol.com.co/noticias/actualidad/cuestionan-contratos-de-seguridad-entre-estado-y-multinacionales/20140108/nota/2050717.aspx

González, L. (2013). Impacto de la minería de hecho en Colombia. Estudios de caso: Quibdó, Istmina, Timbiquí, López de Micay, Guapi, El Charco y Santa Bárbara. Recuperado de https://www.uis.edu.co/webUIS/es/catedraLowMaus/lowMauss13_1/terceraSesion/Impacto $\% 20$ de $\% 201$ a $\% 20$ mineria $\% 20 \mathrm{de} \% 20$ hecho $\% 20$ en $\% 20$ Colombia.pdf

Guerra, M. \& Skewes, V. (2010). Acumulación por desposesión y respuestas locales en el remodelaje de los paisajes esturiales del sur de Chile. Revista de Antropología Chilena, 42(2), 451-463.

Harvey, D. (2004). El "nuevo" imperialismo: acumulación por desposesión. Socialist Register, 40, 99-129.

IIRSA. (2007). Planificación Territorial Indicativa. Grupos Técnicos Ejecutivos - GTE 2007. Recuperado de http://www.iirsa.org/Document/ Detail?Id $=3343$

Isacson, A., Haugaard, L., Poe, A., Kinosian, S. \& Withers, G. (2014). Time to listen: trends in U.S. security assistence to Latin America and the Caribbean. USA: Latin America working group education fund, Center for international policy (CIP), WOLA.

Iscaro, M. E., Petrantonio, M. M. \& Aranguren, C. I. (2010). Lógicas territoriales en tensión. La expansión del agronegocio en el sudeste pampeano. El caso de San Manuel (provincia de Bs. As.)(1976-2010). IV Jornadas Nacionales de Investigadores de las Economías Regionales, Universidad Nacional de Entre Ríos, Facultad de Ciencias Económicas, Paraná.

Isch L. E. (2014). Generación Eléctrica y la Geopolitica Norteamericana. Recuperado de. http://censat.org/es/analisis/generacion-electrica-y-lageopolitica-norteamericana.

Machado Aráoz, H. (2009a). Auge minero y dominación neocolonial en América Latina. Ecología politica de las transformaciones socioterritoriales neoliberales. XXVII Congreso de la Asociación Latinoamericana de Sociología, Buenos Aires.

Machado Aráoz, H. (2009b). Minería transnacional, conflictos socioterritoriales y nuevas dinámicas expropiatorias. El caso de Minera Alum- 
brera. En M. Svampa, \& M.A. Antonelli (Eds.) Minería transnacional, narrativas del desarrollo y resistencias sociales (1 Ed.) (pp. 205-228). Buenos Aires: Biblos.

Machado Aráoz, H. (2010). "El agua vale más que el oro” Grito de resistencia decolonial contra los nuevos dispositivos expropiatorios. En Ecología politica de la minería en América Latina (1 Ed). México: Universidad Nacional Autónoma de México, Centro de Investigaciones Interdisciplinarias en Ciencias y Humanidades.

Machado Aráoz, H. (2013). Extractivismo y "Consenso Social": Expropiación-consumo y fabricación de subjetividades (capitalistas) en contextos neocoloniales. Revista Cuestiones de Población y Sociedad 3, 29-42.

Machado, H. (2014). Territorios y Cuerpos en Disputa. Revista Sociológica de Pensamiento Crítico Intersticios 8(1), 56-71.

Mançano Fernandes, F. (2008). Sobre la tipología de los territorios. Recuperado de http://ebookbrowse.com/bernardo-tipologia-de-territoriosespanol-pdf-d149176315

Massé, F., \& Camargo, J. (2012). Actores armados ilegales y sector extractivo en Colombia. V Informe 2012. Recuperado de http://www.askonline.ch/ fileadmin/user_upload/documents/Thema_Wirtschaft_und_Menschenrechte/Bergbau_Rohstoff/Gold/Actores_armados_ilegales_sector_extractivo.pdf

Ministerio de Minas y Energía. (2013). Decreto 0934. Por el cual se reglamenta el artículo 37 de la Ley 685 de 2001. Diario Oficial 48785 de mayo 9 de 2013. Recuperado de http://www.alcaldiabogota.gov.co/ sisjur/normas/Norma1.jsp?i=53052

Ministerio de Agricultura y Desarrollo Rural-Colombia. (2008). Cajamarca: Despensa agrícola. Boletín mensual. Abastecimiento de alimentos en los principales mercados, 4(3), 1-9. Recuperado de http:/ / www.agronet.gov.co/ www/docs_agronet/2008106152754_Abastecimiento_AbrilM.pdf

Movilización de mujeres afrodescendientes por el cuidado de la vida y los territorios ancestrales. (2014). Comunicados. Recuperado de http:// mujeresnegrascaminan.com/movilizacion/comunicados/

Notiagen- Colectivo Punto de Fuga. (2012). La salvaje Salvajina, el despojo y el oro en Suárez. Recuperado de https://notiagen.wordpress. com/2012/04/02/la-salvaje-salvajina-el-despojo-y-el-oro-en-suarez/

Observatorio de Expansión Minero Energética y Re-existencias, (2015). Titulos Mineros en Suárez. [Mapa]. 
Organización de Naciones Unidas (2011). ¿Qué es el Proceso de Comunidades Negras - PCN? Recuperado de http://www.hchr.org.co/ afrodescendientes/index.php/portada/ique-es-el-proceso-de-comunidades-negras-pcn.html

Osorio, A. \& Galíndez, D. (2009). La entrega de los recursos naturales a la española Unión Fenosa: La represa Salvajina y el trasvase del Río Ovejas. Deslinde, 45, 18-85.

Pulido, A. (2014). Susurros del Magdalena. Los impactos de los megaproyectos en el desplazamiento forzado. Comisión de Ayuda al refugiado. Recuperado de http://www.alainet.org/images/susurros-del-magdalena-baja-resol. pdf

Pineda, C. E. (2012). La dimensión socioambiental del movimiento mapuche en Chile. OSAL 13(32), 135-148. Recuperado de http://biblioteca. clacso.edu.ar/clacso/osal/20120927103642/OSAL32.pdf

Red por la justicia ambiental. (2014). ACCIÓN URGENTE: 12 retroexcavadoras destruyendo el río Ovejas en Suárez, Cauca. Recuperado de http://justiciaambientalcolombia.org/2014/09/15/accion-12-retros-rio-ovejas/

Rico, L. (2010). La Toma por el oro. Recuperado de http://censat.org/es14/ noticias/la-toma-por-el-oro

Rosero, C. (2008). La Consulta previa y el círculo del despojo a las comunidades negras de los municipios de Buenos Aires y Suárez. Revista Semillas, 36-37.

Rudas, G. (2010). Política ambiental del Presidente Uribe, 2002-2010. Niveles de prioridad y retos futuros. Bogotá: Consejo Nacional de Planeación.

Rudas, G. \& Espitia, J. E. (2013). Participación del Estado y la sociedad en la renta minera. En L.J. Garay (Ed.), Minería en Colombia. Fundamentos para superar el modelo extractivista (pp. 125-172). Bogotá D.C.: Contraloría General de la República.

Segrelles, J. A. (1999). Capitalismo y organización de los espacios ganaderos en España. El caso de la Cooperativa Agropecuaria de Guissona. Revista Investigaciones Geográficas, (39), 94-108.

Svampa, M. (2012). Consenso de los commodities, giro ecoterritorial y pensamiento crítico en América Latina. OS AL 13(32), 15-38. Recuperado de http://biblioteca.clacso.edu.ar/clacso/osal/20120927103642/ OSAL32.pdf

Svampa, M. (2013). «Consenso de los Commodities» y lenguajes de valoración en América Latina. Nueva Sociedad, (244), 30-46. 
Unidad de Planeación Minero Energética (UPME). (2014). Plan de expansión de referencia. Generación - Transmisión 2014-2028. Recuperado en http:/ / www.upme.gov.co/Docs/Plan_Expansion/2015/Plan_GT_20142028.pdf

Vanegas, Ó. (2012). Los cándidos de Latinoamérica. Recuperado de http:/ / www. usofrenteobrero.org/index.php/actualidad/boletin-de-junta/1289articulo-qlos-candidos-de-latinoamericaq-por-oscar-vanegas

Vargas Valencia, F. (2013). Minería, conflicto armado y despojo de tierras: impactos,desafíos y posibles soluciones jurídicas. En L.J Garay (Dir.), Minería en Colombia. Fundamentos para superar el modelo extractivista (pp. 57-87). Bogotá D.C.: Contraloría General de la República.

Vega Cantor, R. (2012). Colombia, un ejemplo contemporáneo de acumulación por desposesión. Theomai, 1-24.

Vega Cantor, R. (2014). Extractivismo, enclaves y destrucción ambiental Revista CEPA, 19. Recuperado de http://www.rebelion.org/noticia. php?id=188553

W-Radio. (2014). Cauca: denuncian que 12 retroexcavadoras destruyen el río Ovejas en Suárez. Recuperado de http://www.wradio.com. $\mathrm{co} /$ noticias/actualidad/cauca-denuncian-que-12-retroexcavadorasdestruyen-el-rio-ovejas-en-suarez/20140915/nota/2415608.aspx

Zibechi, R. (2006). IIRS A: la integración a la medida de los mercados. Recuperado de http://www.servindi.org/actualidad/opinion/740 
